ARTIGO ORIGINAL

\title{
Efeito do fogo sobre a regeneração natural e serapilheira na Mata Atlântica
}

\author{
Fire effect on the natural regeneration and litter accumulation in Atlantic \\ Forest \\ Ananda van Doornik Christo ${ }^{1}$ (D), Sebastião Venâncio Martins ${ }^{1}$ (D), Diego Balestrin ${ }^{1}$ (1), \\ Fillipe Tamiozzo Pereira Torres ${ }^{1}$ (D) \\ ${ }^{1}$ Universidade Federal de Viçosa - UFV, Viçosa, MG, Brasil
}

Como citar: Christo, A. V. D., Martins, S. V., Balestrin, D., \& Torres, F. T. P. (2021). Efeito do fogo sobre a regeneração natural e serapilheira na mata atlântica. Scientia Forestalis, 49(130), e3501.

https://doi.org/10.18671/scifor.v49n130.10

\begin{abstract}
Resumo
O estudo e avaliação de indicadores de restauração é fundamental para a definição de medidas e monitoramento de áreas degradadas. Em uma área de Floresta Estacional Semidecidual secundária, com 16 anos de regeneração natural, foi avaliado os efeitos do fogo e da proximidade de remanescentes florestais nativos na produção e acúmulo de serapilheira. Foram demarcadas 20 parcelas de $9 \mathrm{~m}^{2}$, sendo identificado todos os indivíduos com DNS $\geq 30 \mathrm{~cm}$ e CAP $\leq 15 \mathrm{~cm}$ e coletada a serapilheira das parcelas $\left(0,25 \mathrm{~m}^{2}\right)$ e no fragmento adjacente. Foram identificadas 12 espécies e 9 famílias, o índice de Shannon $\left(H^{\prime}=0,427\right)$ e a equabilidade $\left(J^{\prime}=0,166\right)$ demonstraram a baixa diversidade florística da área e dominância da Mabea fistulifera (VI=76\%). Observou-se influência significativa da distância da floresta adjacente sobre a área afetada pelo fogo na produção de serapilheira, sendo recomendado o enriquecimento para aumentar a diversidade da flora local e alavancar o processo de restauração da área.
\end{abstract}

Palavras-chave: Fitossociologia; Incêndio; Restauração florestal.

\begin{abstract}
The study and evaluation of restoration indicators is fundamental to define measures and to monitor degraded areas. In a secondary semi-deciduous seasonal forest area, with 16 years of natural regeneration, the fire effects and the proximity to native forest patch on the yield and accumulation of litter was evaluated. A total of 20 plots of $9 \mathrm{~m}^{2}$ were demarcated, all individuals with $D G L \geq 30 \mathrm{~cm}$ and $\mathrm{CBH} \leq 15 \mathrm{~cm}$ were identified and the litter of each plot $\left(0.25 \mathrm{~m}^{2}\right)$ and at adjacent fragment was collected. Twelve species and nine families were identified. The Shannon' index $\left(\mathrm{H}^{\prime}=\right.$ 0.427 ) and the equability $\left(\mathrm{J}^{\prime}=0.166\right)$ showed a low floristic diversity, aside from the dominance of Mabea fistulifera $(\mathrm{VI}=76 \%)$. Significant influence of the distance of adjacent forest on the fireaffected area and litter production was observed. The enrichment with species to increase the local diversity and to leverage the restoration process of the area is recommended.
\end{abstract}

Keywords: Phytosociology; Burn; Forest restoration.

\section{INTRODUÇÃO}

A alteração da paisagem, resultante de impactos ou distúrbios oriundos tanto de ações antrópicas como naturais, causam, geralmente, inúmeros prejuízos ambientais/ecológicos quando ocorridas em frequência, intensidade e amplitude maiores que o ambiente pode suportar, colocando muitas vezes em risco a segurança pública e o bem-estar social. Neste sentido, a resiliência, que é a habilidade e/ou capacidade do

Fonte de financiamento: Conselho Nacional de Desenvolvimento Científico e Tecnológico (CNPQ).

Conflito de interesse: Nada a declarar.

Autor correspondente: diego.balest@gmail.com

Recebido: 20 outubro 2019.

Aceito: 29 maio 2020.

Editor: Paulo Henrique Müller Silva.

(c) (i) Este é um artigo publicado em acesso aberto (Open Access) sob a licença Creative Commons Attribution, que permite uso, distribuição e reprodução em qualquer meio, sem restrições desde que o trabalho original seja corretamente citado. 
ambiente em "retornar" as condições originas depois de certo distúrbio (Marchese et al., 2018), é condição decisiva para acelerar o processo de restauração e reconstruir certas características especificas destas áreas.

Dentre as inúmeras fontes de perturbação ambiental, o fogo destaca-se entre as mais importantes pelo fato de afetar diretamente o funcionamento dos ecossistemas, incluindo a dinâmica da sucessão vegetal, desenvolvimento e futuro da floresta (Silvério et al., 2013); fragmentação da paisagem (Souza \& Martins, 2004; Carmo et al., 2011); nos serviços ecossistêmicos e potencial econômico (Guimarães et al., 2014); composição e estrutura florestal (Barlow \& Peres, 2008); ciclagem de nutrientes, matéria orgânica (Santana et al., 2019); acúmulo de serapilheira e banco de sementes no solo (Silva \& Matos, 2006); rebrota (Ribeiro et al., 2012); fauna (Aximoff \& Rodrigues, 2011) e microfauna edáfica (Singh et al., 2017); dentre outros. Além disto, como destacado por Bustamante \& Metzger (2019), os distúrbios provocados pelo fogo podem maximizar os efeitos das mudanças climáticas e consequentemente afetar diretamente a população mundial, aumentando assim a vulnerabilidade social em diferentes regiões.

Após a passagem do fogo, a sucessão ecológica e diversidade florística são drasticamente afetadas e alteradas, sendo geralmente reduzida (pelo menos inicialmente) a diversidade das espécies estabelecidas na área (restritas à poucas espécies), como verificado por Barlow \& Peres (2008). Este primeiro estabelecimento vegetal se dá através de diferentes características vegetativas que podem facilitar/auxiliar na entrada ou sobrevivência das espécies nesta área, como por exemplo a presença de rizomas (Ferreira \& Conceição, 2012), arquitetura dos sistemas subterrâneos (Glória \& Cury, 2011), dentre outros.

Neste sentido, alguns ambientes/tipologias florestais, apresentam certa adaptação ou tolerância a incêndios, porém, a maioria sofre severos prejuízos, principalmente na fauna e flora, estando esta resposta do ambiente ligadas ao regime, frequência, intensidade, época de ocorrência e duração (tempo) do fogo, além é claro, das características da vegetação (Camargos et al., 2010).

Assim, a facilidade de dispersão, sobrevivência e/ou adaptação das espécies, que incluem as alterações morfológicas, fenológicas e fisiológicas das plantas (Furquim et al., 2018), são importantes atributos que podem ser utilizados na definição de estratégias de manejo, conservação e restauração de diferentes ambientes alterados por distúrbios (Miranda et al., 2009; Ribeiro et al., 2012). Algumas destas adaptações ou estratégias de proteção contra incêndios estão ligadas à espessura da casca de determinadas espécies (Hoffmann et al., 2009, 2012; Dantas et al., 2013); armazenamento de água em tecidos e raízes, espessura das folhas e sua relação carbono-nitrogênio (Scholz et al., 2007; Schymanski et al., 2013), dentre outras caraterísticas.

Contudo, ainda são poucos os estudos sobre a dinâmica da regeneração natural e serapilheira em áreas que sofreram distúrbios por incêndios em Florestas Estacionais Semideciduais, que, de acordo com trabalhos realizados por (Martins \& Ribeiro, 2002; Martins et al., 2002; Silva et al., 2005; Rodrigues et al., 2005; Camargos et al., 2010; Xavier et al., 2011), apresentam uma grande variação das respostas ambientais ao impacto, incluindo a capacidade de regeneração, dinâmica sucessional, composição e densidade de espécies.

Neste sentido, conforme observado por Rodrigues et al. (2009), a reconstrução do ambiente, particularmente na Mata Atlântica, com alta diversidade e sustentabilidade é viável, porém depende da aplicação de boas estratégias/técnicas e de levar em consideração as características da paisagem circundante. Neste sentido, a busca pela compreensão do comportamento e dinâmica de áreas alteradas é fundamental para a tomada de decisões em vista da restauração ecológica destes locais.

Diante disto, os objetivos deste estudo foram caracterizar a florística da regeneração natural e a variação no acúmulo da serapilheira em relação a distância de uma área de Floresta Estacional Semidecidual não atingida pelo fogo, evento este que ocorreu em 1999 
e foi avaliado passados 16 anos da sua incidência. Além disto, este trabalho buscou produzir informações úteis para a restauração de áreas impactadas por incêndios.

\section{MATERIAL E MÉTODOS}

\subsection{Descrição da área de estudo}

A área de estudo se localiza em um trecho de Floresta Estacional Semidecidual secundária, situada no Campus da Universidade Federal de Viçosa, município de Viçosa, MG. A área compreende um fragmento de floresta nativa com aproximadamente 22 ha, que após a ocorrência de um incêndio em agosto de 1999, destruiu uma área de aproximadamente 12 ha, eliminado toda a cobertura vegetal existente e causando uma forte alteração da paisagem local, principalmente na área do estudo, que foi o trecho mais drasticamente afetado (Figura 1).

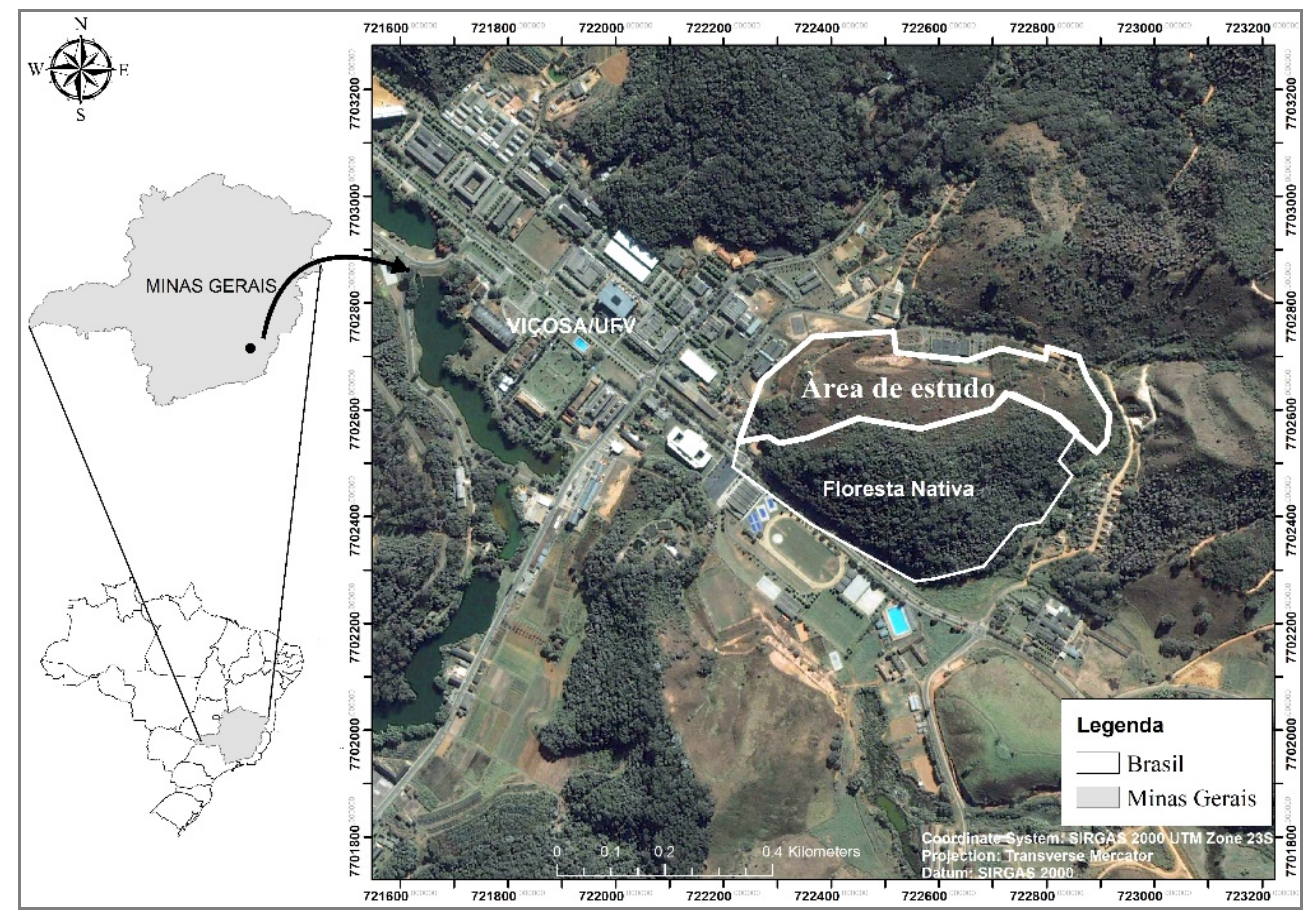

Figura 1- Localização da área de estudo (em destaque).

De acordo com a classificação de Köeppen, o clima da região é do tipo Cwb, mesotérmico com verões chuvosos e invernos frios e secos. A temperatura média anual é de $20^{\circ} \mathrm{C}$ e a umidade relativa do ar varia em torno de $81 \%$, sendo a precipitação média anual de 1.268,2 mm (Lorenzon et al., 2013).

A topografia da região é acidentada e com atitude média de $650 \mathrm{~m}$. Os solos predominantes nos topos e nas encostas das elevações são os latossolos Vermelho-Amarelo Álico e, nos terraços, o Podzólico Vermelho-Amarelo Câmbico (Meira-Neto \& Martins, 2000).

Em relação à época de ocorrência do incêndio (agosto/1999), através da análise do cenário climático do corrente ano pelo índice de risco de incêndios (FWI), observou-se que os meses de agosto e setembro foram os que apresentaram os maiores valores do ano. Além disto, este comportamento também pode ser observado em relação a umidade relativa do ar, demonstrando assim a relação dos efeitos climáticos na ocorrência do evento ocorrido.

Após a passagem do fogo pela área, houve o estabelecimento do campim-gordura (Melinis minutiflora P.Beauv.) em praticamente toda a área afetada, formando uma agressiva cobertura que pode ter prejudicado o processo de regeneração natural de espécies florestais nativas na área. A avaliação do trecho em questão foi realizada 16 anos após a incidência do incêndio, estando a área amostrada inserida nas proximidades/limite do trecho florestal 
nativo não atingido pelo fogo (caracterizado como um fragmento de mata secundária e em estágio médio de sucessão).

\subsection{Amostragem da vegetação e serapilheira}

Foram demarcadas 20 parcelas de $3 \times 3 \mathrm{~m}\left(9 \mathrm{~m}^{2}\right)$, totalizando $180 \mathrm{~m}^{2}$, que foram sistematicamente lançadas em intervalos de $5 \mathrm{~m}$ (Figura 2) na área mais afetada pelo fogo (destruição total da cobertura vegetal). As parcelas foram divididas em 5 transectos de acordo o distanciamento da floresta adjacente. Esta floresta se caracteriza por estar em estágio médio de regeneração e não ter sido atingida diretamente pelo fogo.

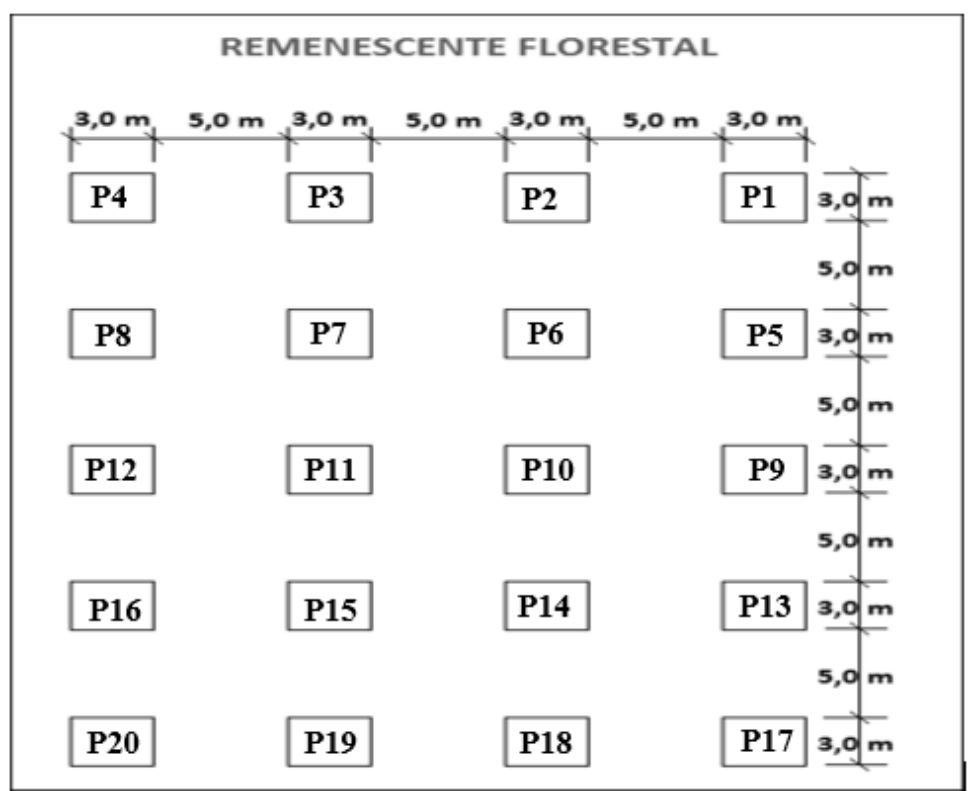

Figura 2- Esquema de amostragem realizada na área de estudo.

Para a análise da regeneração natural, foi realizada a medição da altura e diâmetro ao nível do solo (DNS) de todos os indivíduos com altura $\geq 30 \mathrm{~cm}$ e circunferência à altura do peito (CAP) $\leq 15 \mathrm{~cm}$ existentes em cada parcela, sendo identificados a nível de espécie e família botânica. Além disto, as espécies encontradas foram identificadas segundo o sistema de classificação APG IV (Angiosperm Phylogeny Group, 2016) e classificadas em grupos ecológicos de acordo com a metodologia adaptada por Gandolfi et al. (1995) para florestas semidecíduas brasileiras, sendo estas: pioneiras, secundárias iniciais e secundárias tardias. Quanto a síndrome de dispersão dos propágulos, as espécies vegetais foram classificadas em: zoocóricas, anemocóricas e autocóricas (van der Pijl, 1982).

Para a avaliação da serapilheira acumulada, através do auxílio de um gabarito com área de $0,25 \mathrm{~m}^{2}$, no centro de cada parcela foram coletadas amostras de material vegetal depositado sobre a superfície do solo (folhas, galhos, frutos e flores). A fim de comparar os quantitativos de serapilheira acumulada com a mata adjacente não atingida pelo fogo, foram coletadas 20 amostras de serapilheira dentro do fragmento (utilizando a mesma metodologia amostral de distribuição das parcelas e transectos utilizados na avaliação da regeneração natural). Esta amostragem foi realizada no mês de outubro, ou seja, logo após o término da estação seca e início da estação chuvosa.

As amostras coletadas foram armazenadas em sacos de papel devidamente identificados e secas em estufa à $70^{\circ} \mathrm{C}$ até estabilização do peso. Assim, após pesagem em balança de precisão, obteve-se a massa seca da serapilheira acumulada em cada uma das áreas e amostras, sendo estes valores extrapolados para hectare.

Com isto, pode-se determinar e comparar as variações de serapilheira acumulada existentes na área atingida pelo fogo e no fragmento adjacente (conservado), bem como a influência da distância deste último no acúmulo de material. 


\subsection{Análise dos dados}

Para análise dos dados fitossociológicos da regeneração existente, foi utilizado o programa FITOPAC 2.1 Shepherd (2010), sendo a estrutura fitossociológica horizontal expressa mediante os parâmetros de densidade e frequência. Além disto, quantificou-se o valor de importância (VI), índice de diversidade de Shannon ( $\left.\mathrm{H}^{\prime}\right)$ e o índice de equabilidade de Pielou (J').

\section{RESULTADOS E DISCUSSÃO}

Foram identificadas 12 espécies arbóreas pertencentes a 9 famílias botânicas. 0 índice de diversidade de Shannon $\left(\mathrm{H}^{\prime}\right)$ foi de 0,427 e a equabilidade de Pielou $\left(\mathrm{J}^{\prime}\right)=0,166$, sendo ambos considerados baixos quando comparados com os valores encontrados na região (Campos et al., 2006; Higuchi et al., 2006).

De acordo com os parâmetros fitossociológicos das espécies encontradas na regeneração natural da área em estudo, observou-se o maior valor de importância $(\mathrm{VI}=76 \%)$ para a espécie Mabea fistulifera, consequência de sua presença em maior número diante das demais (domínio), seguida da espécie Erythoxylum pelleterianum, com VI=8,1\%. Na Tabela 1 a seguir, são apresentados os parâmetros fitossociológicos, categorias sucessionais e síndrome de dispersão de cada espécie encontrada na área.

Tabela 1- Florística e parâmetros fitossociológicos das espécies encontradas na regeneração natural após incêndio na área de estudo.

\begin{tabular}{|c|c|c|c|c|c|c|}
\hline Famílas/Espécies & $\mathbf{N}$ & DR & FR & VI\% & SD & CS \\
\hline \multicolumn{7}{|l|}{ Euphorbiaceae } \\
\hline Mabea fistulifera Mart. & 315 & 92,38 & 50,00 & 76 & Auto & SI \\
\hline \multicolumn{7}{|l|}{ Erythroxylaceae } \\
\hline Erythroxylum pelleterianum A.St.-Hil. & 9 & 2,64 & 16,67 & 8,1 & Zoo & SI \\
\hline \multicolumn{7}{|l|}{ Lacistemataceae } \\
\hline Lacistema pubescens Mart. & 5 & 1,47 & 5,56 & 2,6 & Zoo & $\mathrm{SI} / \mathrm{ST}$ \\
\hline \multicolumn{7}{|l|}{ Fabaceae } \\
\hline Copaifera langsdorffii Desf. & 1 & 0,29 & 2,78 & 2,41 & Zoo & SI \\
\hline \multicolumn{7}{|l|}{ Myrtaceae } \\
\hline Eugenia florida DC. & 1 & 0,29 & 2,78 & 1,91 & Zoo & ST \\
\hline \multicolumn{7}{|l|}{ Lamiaceae } \\
\hline Aegiphila sellowiana Cham. & 1 & 0,29 & 2,78 & 1,86 & Zoo & SI \\
\hline \multicolumn{7}{|l|}{ Melastomataceae } \\
\hline Miconia cinnamomifolia (DC.) Naudin & 3 & 0,88 & 2,78 & 1,5 & Zoo & $\mathrm{P}$ \\
\hline \multicolumn{7}{|l|}{ Fabaceae } \\
\hline Piptadenia gonoacantha (Mart.) J.F.Macbr. & 1 & 0,29 & 2,78 & 1,3 & Auto & $\mathrm{SI}$ \\
\hline \multicolumn{7}{|l|}{ Myrtaceae } \\
\hline Psidium guajava L. & 1 & 0,29 & 2,78 & 1,11 & Zoo & $P$ \\
\hline \multicolumn{7}{|l|}{ Myrsinaceae } \\
\hline Myrsine coriacea (Sw.) R.Br. ex Roem. and Schult. & 1 & 0,29 & 2,78 & 1,1 & Zoo & $P$ \\
\hline \multicolumn{7}{|l|}{ Melastomataceae } \\
\hline Miconia albicans (Sw.) Triana & 1 & 0,29 & 2,78 & 1,06 & Zoo & $P$ \\
\hline \multicolumn{7}{|l|}{ Rubiaceae } \\
\hline Psychotria velloziana Benth. & 1 & 0,29 & 2,78 & 1,05 & Zoo & $\mathrm{SI} / \mathrm{ST}$ \\
\hline
\end{tabular}

$\mathrm{N}=$ número de indivíduos; $\mathrm{DR}=$ densidade relativa; $\mathrm{FR}=$ freqüência relativa; $\mathrm{VI}=\mathrm{valor}$ de importância; $\mathrm{VI} \%=\mathrm{valor}$ de importância relativo. CS: Categoria sucessional (P: pioneiras, SI: secundárias iniciais e ST: secundárias tardias. SD: Síndrome de Dispersão (Auto: autocórica e Zoo: zoocórica). 
O domínio da Mabea fistulifera pode ser explicado pela sua alta capacidade de rebrota pelo tronco e pela raiz, como verificado por Souza et al. (2015); presença de mecanismos de proteção na planta, como os "marginal colleters", conforme Paiva (2012); elevada dispersão com distribuição agrupada (Boubli et al., 2011), sendo esta espécie frequentemente encontrada em fragmentos na Zona da Mata Mineira e também característica das Florestas Estacionais Semideciduais do estado (Ferreira Júnior et al., 2007), assim como pela possível interação mutualística com formigas através da dispersão secundária, como visualizado por Peternelli et al. (2004).

Outra hipótese é que, devido a perturbação ocorrida (incêndio), esta espécie (Mabea fistulifera), pode ter ocupado os outros estratos e/ou apresentado alta dominância na área, diferentemente do padrão encontrado naturalmente em florestas preservadas, como observado no estudo de Reis et al. (2018) em uma área do entorno com 18 meses após a passagem do fogo, na qual foi observada uma alta regeneração de Cecropia sp. Neste sentido, o fogo pode atuar como um agente de "seleção" de espécies que melhor se adaptam às condições especificas da área após determinado distúrbio (Silva et al., 2011).

Estudos realizados nesta mesma área, porém 6 meses após o incêndio, demonstraram maior montante de espécies e maior diversidade quando comparado com o levantamento atual (16 anos após o incêndio). Conforme apresentado por Martins et al. (2002), após 6 meses do incêndio foram encontradas 75 espécies de 26 famílias botânicas distintas e maior riqueza da família Asteraceae (53,8\%), seguida da Poaceae (38,4\%). Tais resultados podem indicar a influência variável a médio e longo prazos dos efeitos do fogo nesta área (mortalidade de indivíduos devido a entrada de doenças, danos, etc), bem como o avanço do processo sucessional, que, naturalmente/geralmente ocasiona redução da diversidade de espécies nos níveis mais avançados de sucessão (Gandolfi, 2000).

Quanto a síndrome de dispersão, observou-se que 83,33\% das espécies apresentaram dispersão por zoocoria, além de a maioria pertencerem ao grupo ecológico das pioneiras e secundárias iniciais, revelando assim o estádio sucessional da floresta em formação, que a classifica como uma floresta inicial, formada em sua maioria por espécies de rápido crescimento e de elevada dispersão por sementes. Confirmando estes resultados para florestas iniciais, pode-se citar os trabalhos de Yamamoto et al. (2007), Dan et al. (2010) e Stefanello et al. (2010).

Através da avaliação da similaridade florística entre as parcelas, observou-se, no geral, certa tendência na formação de grupos de acordo com a proximidade das parcelas e também em relação aos transectos, que podem indicar certa influência do fragmento adjacente na regeneração desta área (Figura 3).

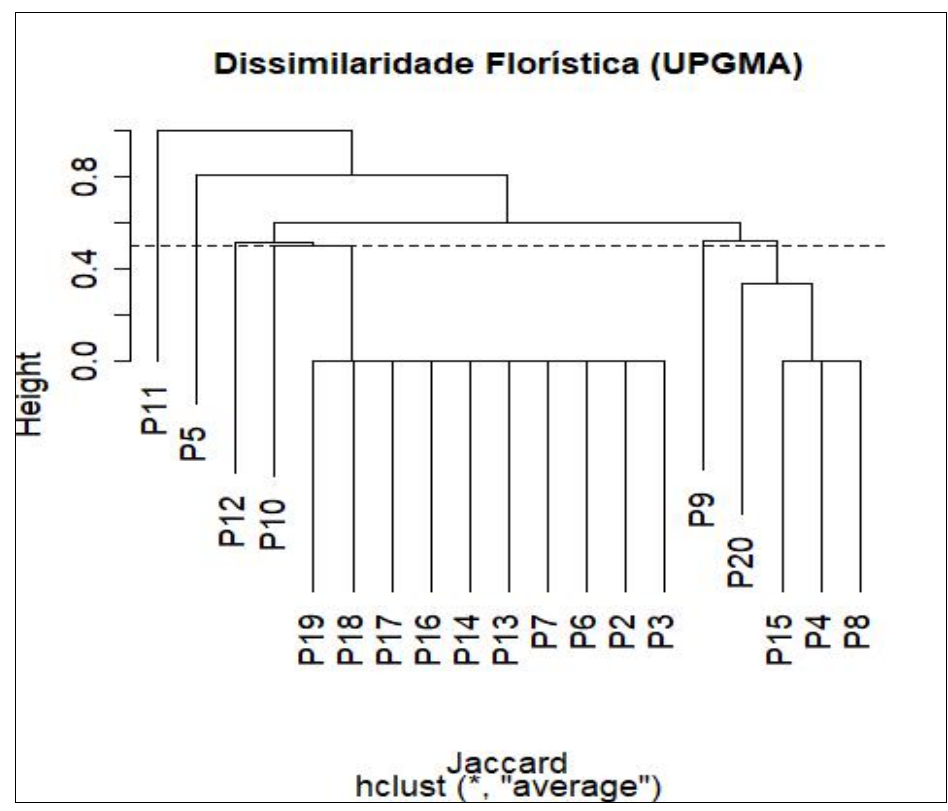

Figura 3- Dissimilaridade florística entre as parcelas alocadas na área de estudo. 
Neste mesmo sentido, no tocante ao acúmulo de serapilheira nas parcelas em relação a distância do fragmento conservado de floresta, observou-se uma tendência de redução dos montantes totais conforme o afastamento do fragmento, como é observado na Figura 4.

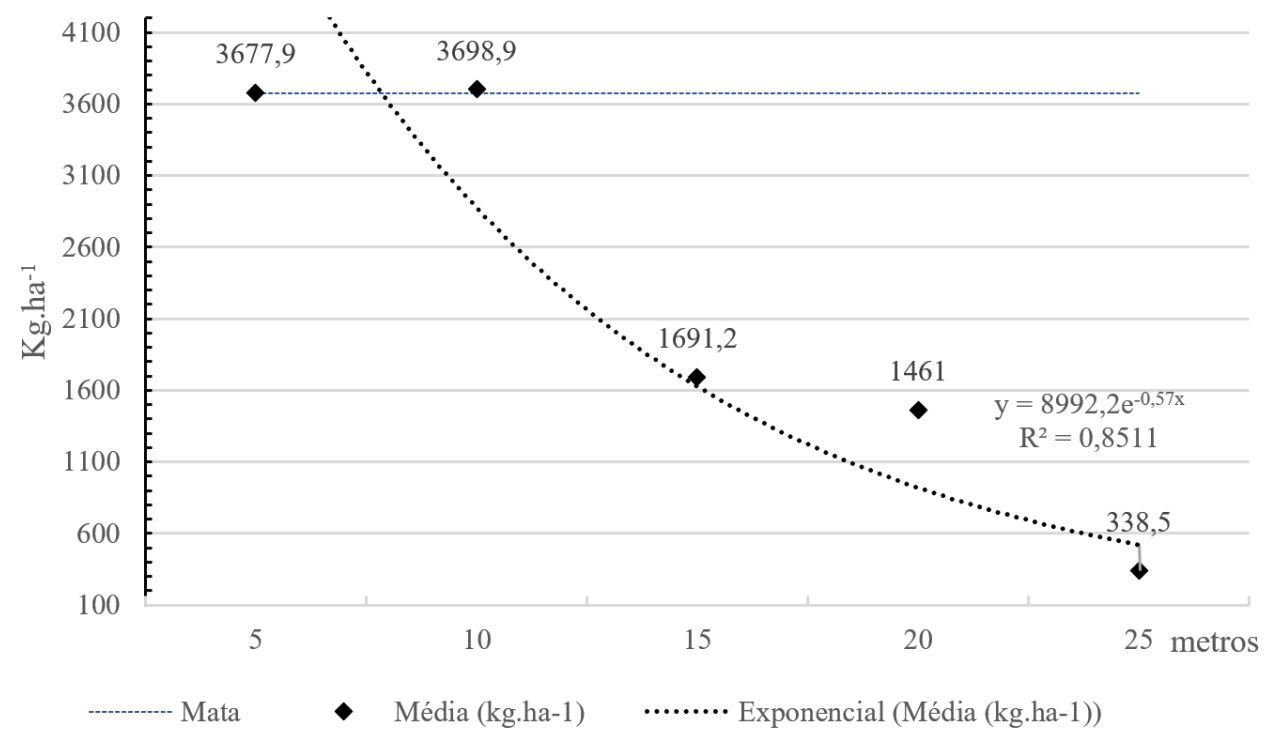

Figura 4- Variação do acúmulo de serapilheira em função da distância do fragmento conservado.

No tocante a serapilheira acumulada no fragmento adjacente (mata conservada), verificouse uma média de $3671,4 \mathrm{~kg} \mathrm{ha}^{-1}$, estando os transectos a 5 e 10 metros de distância com valores próximos ao verificado na mata conservada, o que confirma a influência direta da mata no processo de acúmulo de serapilheira e sua importância no processo de restauração. Estes montantes superiores de serapilheira acumulada nos transectos à 5 e 10 metros do remanescente florestal nativo não atingido pelo fogo, podem ser explicados pela chegada de propágulos da mata adjacente (proximidade espacial), além da influência do sombreamento no controle do capim-gordura (Melinis minutiflora P.Beauv.) na área.

Além disto, conforme exposto por Kageyama \& Gandara (2000), esta proximidade com fragmentos florestais nativos pode colaborar com o processo de restauração ambiental da área devido à proximidade com as fontes de propágulos, fluxo da fauna, dentre outros elementos que auxiliam/facilitam o processo de estabelecimento vegetal e o avanço sucessional de áreas alteradas. Em contrapartida, nas áreas mais distantes do fragmento florestal nativo não afetado pelo fogo, houve maior presença de capim-gordura, podendo este ser responsável pela baixa germinação e desenvolvimento das plântulas de espécies arbustivas e arbóreas nativas nestes locais, explicando assim a baixa regeneração e produção de serapilheira.

Neste sentido, apesar do tempo decorrido após a passagem do fogo, a presença dominante da gramínea invasora Melinis minutiflora na área atingida pelo fogo demonstra a sua influência marcante no avanço do processo sucessional da área (Martins et al., 2002). Isto acontece devido sua agressividade, que pode atrasar ou inibir o processo de regeneração natural (Matos \& Pivello, 2009), formando uma barreira (impedimento físico) e reduzindo a luminosidade e consequentemente a germinação e desenvolvimento das plântulas e/ou brotos (Souza et al., 2015).

$\mathrm{Na}$ comparação entre as espécies encontradas no levantamento 6 meses após a passagem do fogo com o levantamento atual (12 anos após o incêndio), foi verificado a baixa permanência das espécies que anteriormente haviam rebrotado, sendo apenas $16,6 \%$ delas encontradas no atual levantamento, indicando assim uma baixa sobrevivência a médio prazo. Além disso, verificou-se que do total das espécies que apresentaram rebrotas 6 meses após a passagem do fogo, as únicas espécies que ainda se encontravam no povoamento eram: Mabea fistulifera, Erythroxylum pelleterianum, Piptadenia gonoacantha e Aegiphila sellowiana. 
Esta influência na germinação e permanência de determinadas espécies após a passagem do fogo, também foi observada por Melo et al. (2007) e Camargos et al. (2010, 2013), podendo estar diretamente relacionado ao tempo e intensidade do fogo ocorrido na área. Neste sentido, algumas características como: profundidade da semente no topsoil, características e espessura do tegumento das sementes, dormência da semente (especialmente para espécies que respondem positivamente à quebra de dormência pelo fogo), capacidade de rebrota e outras características específicas de certas espécies, podem influenciar na permanência e desenvolvimento de espécies após a passagem do fogo.

Diante disto, percebe-se a fragilidade do ambiente aos impactos ocasionados com a passagem do fogo, que em um primeiro momento pode demonstrar certa resposta positiva através da rebrota de indivíduos, mas, a médio e longo prazo, podem não apresentar viabilidade na sobrevivência, necessitando mais estudos a respeito desta trajetória e constante monitoramento.

\section{CONCLUSÃO}

A área se caracteriza como uma floresta em estágio inicial de sucessão e que, apesar da baixa diversidade de espécies, domínio da espécie Mabea fistulifera Mart. e presença de gramíneas invasoras (Melinis minutiflora P.Beauv.), vem avançando no processo sucessional ao longo do tempo. Contudo, pode-se sugerir a utilização de técnicas de enriquecimento e/ou plantio em núcleos de diversidade de espécies nativas da região para aumentar a riqueza florística, controlar as espécies invasoras e restabelecer as funções ecológicas da área, justificando assim a importância deste tipo de estudos para a tomada de decisões em projetos de restauração ecológica.

A distância do fragmento conservado influencia diretamente no acúmulo de serapilheira na área impactada pelo fogo, demonstrando assim a importância dos remanescentes florestais no avanço do processo sucessional de uma área alterada.

Por fim, estas informações podem servir de base para a definição das melhores técnicas a serem utilizadas em projetos de restauração em função da proximidade ou não de fragmentos florestais nativos que, claramente, demonstram a conexão existente com a paisagem e o ambiente circundante.

\section{REFERÊNCIAS}

Angiosperm Phylogeny Group - APG IV. (2016). An update of the Angiosperm Phylogeny Group classification for the orders and families of flowering plants: APG IV. Botanical Journal of the Linnean Society, 181(1), 1-20. http://dx.doi.org/10.1111/boj.12385.

Aximoff, I., \& Rodrigues, R. C. (2011). Histórico dos incêndios florestais no Parque Nacional do Itatiaia. Ciência Florestal, 21(1), 83-92. http://dx.doi.org/10.5902/198050982750.

Barlow, J., \& Peres, C. A. (2008). Fire-mediated dieback and compositional cascade in an Amazonian forest. Philosophical Transactions of the Royal Society of London. Series B, Biological Sciences, 363(1498), 1787-1794. PMid:18267911. http://dx.doi.org/10.1098/rstb.2007.0013.

Boubli, J. P., Santos, F. C., \& Strier, K. B. (2011). Structure and floristic composition of one of the last forest fragments containing the critically endangered northern Muriqui (Brachyteles hypoxanthus, primates). Ecotropica, 17, 53-69. Recuperado em 9 de novembro de 2018, de https://www.soctropecol.eu/PDF/Ecotropica_2011/Boubli_et_al_2011.pdf

Bustamante, M. M. C., \& Metzger, J. P. (2019). Tendências e impactos dos vetores de degradação e restauração da biodiversidade e dos serviços ecossistêmicos. In C. A. Joly, F. R. Scarano, C. S. Seixas, J. P. Metzger, J. P. Ometto, M. M. C. Bustamante, M. C. G. Padgurschi, A. P. F. Pires, P. F. D. Castro, T. Gadda \& P. Toledo (Eds.), $1^{\circ}$ diagnóstico brasileiro de biodiversidade e serviços ecossistêmicos (No. 3, pp. 93-213). São Carlos: Editora Cubo.

Camargos, V. L., Martins, S. V., Ribeiro, G. A., Carmo, F. M. S., \& Silva, A. F. (2010). Avaliação do impacto do fogo no estrato de regeneração em um trecho de floresta estacional semidecidual em Viçosa, MG. Revista Árvore, Viçosa-MG, 34(6), 1055-1063. http://dx.doi.org/10.1590/S010067622010000600011. 
Camargos, V. L., Martins, S. V., Ribeiro, G. A., Carmo, F. M. S., \& Silva, A. F. (2013). Influência do fogo no banco de sementes do solo em Floresta Estacional Semidecidual. Ciência Florestal, 23(1), 19-28. http://dx.doi.org/10.5902/198050988436.

Campos, E. P., Silva, A. F., Meira Neto, J. A. A., \& Martins, S. V. (2006). Florística e estrutura horizontal da vegetação arbórea de uma ravina em um fragmento florestal no município de Viçosa, MG. Revista Árvore, 30(6), 1045-1054. http://dx.doi.org/10.1590/S0100-67622006000600021.

Carmo, A. B., Vasconselos, H. L., \& Araújo, G. M. (2011). Estrutura da comunidade de plantas lenhosas em fragmentos de cerrado: relação com o tamanho do fragmento e seu nível de perturbação. Revista Brasil. Bot., 34(1), 31-38. http://dx.doi.org/10.1590/S0100-84042011000100004.

Dan, M. L., Braga, J. M. A., \& Nascimento, M. T. (2010). Estrutura da comunidade arbórea de fragmentos de floresta estacional semidecidual na bacia hidrográfica do rio São Domingos, Rio de Janeiro, Brasil. Rodriguésia, 61(4), 749-766. http://dx.doi.org/10.1590/2175-7860201061414.

Dantas, V. L., Batalha, M. A., \& Pausas, J. G. (2013). Fire drives functional thresholds on the savannaforest transition. Ecology, 94(11), 2454-2463. PMid:24400497. http://dx.doi.org/10.1890/12-1629.1.

Ferreira Júnior, W. G., Silva, A. F., da, Neto, J. A. A. M., Schaefer, C. E. G. R., \& Dias, A. (2007). Composição florística da vegetação arbórea de um trecho de Floresta Estacional Semidecídua em Viçosa, Minas Gerais, e espécies de maior ocorrência na região. Revista Árvore, 31(6), 1121-1130. http://dx.doi.org/10.1590/S0100-67622007000600018.

Ferreira, M. M. A de A., \& Conceição, A. A. (2012). Alocação preferencial de recursos e morfologia de órgãos subterrâneos em plantas resistentes ao fogo em vegetação campestre. Sitientibus. Série Ciências Biológicas, 12(1), 143-149. http://dx.doi.org/10.13102/scb114.

Furquim, L. C., Santos, M. P., Andrade, C. A. O., Oliveira, L. A., \& Evangelista, A. W. P. (2018). Relação entre plantas nativas do cerrado e água. Científic@-Multidisciplinary Journal, 5(2), 146-156. http://dx.doi.org/10.29247/2358-260X.2018v5i2.p146-156.

Gandolfi, S. (2000). História natural de uma Floresta Estacional Semidecidual no município de Campinas (São Paulo, Brasil) (Tese de doutorado). Campinas: Universidade Estadual de Campinas. Recuperado em 9 de novembro de 2018, de http://repositorio.unicamp.br/jspui/handle/REPOSIP/314916

Gandolfi, S., Leitão Filho, H. F., \& Bezerra, C. L. F. (1995). Levantamento florístico e caráter sucessional das espécies arbustivo-arbóreas de uma floresta mesófila semidecidual no município de Guarulhos, SP. Revista Brasileira de Biologia, 55(4), 753-767. Recuperado em 9 de novembro de 2018, de http://www.Icb.esalq.usp.br/publications/articles/1995/1995rbbv55n4p753-767.pdf

Glória, B. A., \& Cury, G. (2011). Morpho-anatomical features of underground systems in six Asteraceae species from the Brazilian Cerrado. Annals of the Brazilian Academy of Sciences, 83(3), 981-991. PMid:21779656. http://dx.doi.org/10.1590/S0001-37652011005000018.

Guimarães, P. P., Souza, S. M. D., Fiedler, N. C., \& Silva, A. G. (2014). Análise dos impactos ambientais de um incêndio florestal. Agrarian Academy. Centro Científico Conhecer, 1(1), 38-60. Recuperado em 30 de março de 2020, de http://www.conhecer.org.br/Agrarian\%20Academy/2014a/analise\%20dos\%20impactos.pdf

Higuchi, P., Reis, M. G. F., Reis, G. G., Pinheiro, A., Silva, C. T., \& Oliveira, C. H. R. (2006). Composição florística da regeneração natural de espécies arbóreas ao longo de oito anos em um fragmento de floresta estacional semidecidual, em Viçosa, MG. Revista Árvore, Viçosa-MG, 30(6), 893-904. http://dx.doi.org/10.1590/S0100-67622006000600004.

Hoffmann, W. A., Adasme, R., Haridasan, M., Carvalho, M. T., \& Geiger, E. L. (2009). Tree topkill, not mortality, governs the dynamics of savanna-forest boundaries under frequent fire in central Brazil. Ecology, 90(5), 1326-1337. PMid:19537552. http://dx.doi.org/10.1890/08-0741.1.

Hoffmann, W., Geiger, E. L., Gotsch, S. G., Rossatto, D. R., Silva, L. C. R., Lau, O. L., Haridasan, M., \& Franco, A. C. (2012). Ecological thresholds at the savanna-forest boundary: how plant traits, resources and fire govern the distribution of tropical biomes. Ecology Letters, 15(7), 759-768. http://dx.doi.org/10.1111/j.1461-0248.2012.01789.x.

Kageyama, P. Y., \& Gandara, F. B. (2000). Recuperação de áreas ciliares. Matas Ciliares: Conservação e Recuperação, 2, 249-269.

Lorenzon, A. S., Dias, H. C. T., \& Leite, H. G. (2013). Precipitação efetiva e interceptação da chuva em um fragmento florestal com diferentes estágios de regeneração. Revista Árvore, 37(4), 619-627. http://dx.doi.org/10.1590/S0100-67622013000400005.

Marchese, D., Reynolds, E., Bates, M. E., Morgan, H., Clark, S. S., \& Linkov, I. (2018). Resilience and sustainability: similarities and differences in environmental management applications. The Science 
of the Total Environment, 613-614, 1275-1283. PMid:28962075. http://dx.doi.org/10.1016/j.scitotenv.2017.09.086.

Martins, S. V., \& Ribeiro, G. A. (2002). Initial secondary succession in a Forest fragmente disturbed by fire in Viçosa - MG. In D. X. Viegas (Ed.), Forest fire research and wildland fire safety (pp. 1-9). Rotterdam: Millpress.

Martins, S. V., Ribeiro, G. A., Silva Junior, W. M., \& Nappo, M. E. (2002). Regeneração pós-fogo em um fragmento de Floresta Estacional Semidecidual no município de Viçosa, MG. Ciência Florestal, 12(1), 11-19. http://dx.doi.org/10.5902/198050981696.

Matos, D. M. S., \& Pivello, V. R. (2009). O impacto das plantas invasoras nos recursos naturais de ambientes terrestres: alguns casos brasileiros. Ciência e Cultura, 61(1), 27-30. Recuperado em 30 de março de 2020, de http://cienciaecultura.bvs.br/scielo.php?script=sci_arttext\&pid=S000967252009000100012

Meira-Neto, J. A. A., \& Martins, F. R. (2000). Estrutura da Mata da Silvicultura, uma floresta estacional semidecidual montana no município de Viçosa, MG. Revista Árvore, 21(2), 151-160.

Melo, A. C. G., Durigan, G., \& Gorenstein, M. R. (2007). Efeito do fogo sobre o banco de sementes em faixa de borda de Floresta Estacional Semidecidual, SP, Brasil. Acta Botanica Brasílica, 21(4), 927-934. http://dx.doi.org/10.1590/S0102-33062007000400017.

Miranda, H. S., Sato, M. N., Nascimento Neto, W., \& Aires, F. S. (2009). Fires in the cerrado, the Brazilian savanna. In M. A. Cochrane (Ed.), Tropical fire ecology (pp. 427-450). Switzerland: Springer. http://dx.doi.org/10.1007/978-3-540-77381-8_15.

Paiva, E. A. S. (2012). Colleters in Cariniana estrellensis (Lecythidaceae): structure, secretion and evidences for young leaf protection. The Journal of the Torrey Botanical Society, 139(1), 1-8. http://dx.doi.org/10.3159/TORREY-D-11-00046.1.

Peternelli, E. F. O., Della Lucia, T. M. C., \& Martins, S. V. (2004). Espécies de formigas que interagem com as sementes de Mabea fistulifera Mart. (Euphorbiaceae). Revista Árvore, 28(5), 733-738. http://dx.doi.org/10.1590/S0100-67622004000500013.

Reis, B. P., Zatelli, K. S., Torres, F. T. P., \& Martins, S. V. (2018). Influence of fire on the natural regeneration of a semideciduous seasonal rainforest fragment. Floresta e Ambiente, 25(4), 9p. http://dx.doi.org/10.1590/2179-8087.017417.

Ribeiro, M. N., Sanchez, M., Pedroni, F., \& Peixoto, K da S. (2012). Fogo e dinâmica da comunidade lenhosa em cerrado sentido restrito, Barra do Garças, Mato Grosso. Acta Botanica Brasílica, 26(1), 203-217. http://dx.doi.org/10.1590/S0102-33062012000100020.

Rodrigues, R. R., Lima, A. F. L., Gandolfi, S., \& Nave, A. G. (2009). On the restoration of high diversity forests: 30 years of experience in the Brazilian Atlantic Forest. Biological Conservation, 142(6), 12421251. http://dx.doi.org/10.1016/j.biocon.2008.12.008.

Rodrigues, R. R., Martins, S. V., \& Matthes, L. H. F. (2005). Post-fire regeneration in a semideciduous mesophytic forest, south-easthern Brazil. In A. R. Burk (Ed.). New research on forest ecosystems (pp. 1-19). New York: Nova Science Publishers. Recuperado em 10 de novembro de 2018, de http://www.lerf.esalq.usp.br/divulgacao/tecnicos/rodrigues2006.pdf

Santana, T. F., Fernandes, H. E., Giongo, M., Moura, W. S., Cabral, K. P., \& Souza, P. B. (2019). Influência do fogo na germinação de três espécies do bioma Cerrado. Biodiversidade, 18(1), 18-27. Recuperado em 30 de março de 2020, de http://www.periodicoscientificos.ufmt.br/ojs/index.php/biodiversidade/article/view/8232/5468

Scholz, F. G., Bucci, S. J., Goldstein, G., Meinzer, F. C., Franco, A. C., \& Miralles-Wilhelm, F. (2007). Biophysical properties and functional significance of stem water storage tissues in Neotropical savanna trees. Plant, Cell \& Environment, 30(2), 236-248. PMid:17238914. http://dx.doi.org/10.1111/j.1365-3040.2006.01623.x.

Schymanski, S. J., Or, D., \& Zwieniecki, M. (2013). Stomatal control and leaf thermal and hydraulic capacitances under rapid environmental fluctuations. PLoS One, 8(1), e54231. PMid:23359800. http://dx.doi.org/10.1371/journal.pone.0054231.

Shepherd, G. J. (2010). Fitopac, version 2.1. 2.85. Campinas: Departamento de Botânica, Universidade Estadual de Campinas.

Silva, D. M., Loiola, P de P., Rosatti, N. B., Silva, I. A., Cianciaruso, M. V., \& Batalha, M. A. (2011). Os efeitos dos regimes de fogo sobre a vegetação de cerrado no Parque Nacional das Emas, GO: considerações para a conservação da diversidade. Biodiversidade Brasileira, 2, 1-14. Recuperado em 10 de novembro de 2018, de https://www.icmbio.gov.br/revistaeletronica/index.php/BioBR/article/view/136/102 
Silva, U. S. R., \& Matos, D. M. S. (2006). The invasion of Pteridium aquilinum and the impoverishment of the seed bank in fire prone areas of Brazilian Atlantic Forest. Biodiversity and Conservation, 15(9), 3035-3043. http://dx.doi.org/10.1007/s10531-005-4877-z.

Silva, V. F., Oliveira-Filho, A. D., Venturin, N., Carvalho, W. A. C., \& Gomes, J. B. V. (2005). Impacto do fogo no componente arbóreo de uma floresta estacional semidecídua no município de Ibituruna, MG, Brasil. Acta Botanica Brasílica, 19(4), 701-716. http://dx.doi.org/10.1590/S0102-33062005000400005.

Silvério, D. V., Brando, P. M., Balch, J. K., Putz, F. E., Nepstad, D. C., Oliveira-Santos, C., \& Bustamante, M. M. (2013). Testing the Amazon savannization hypothesis: fire effects on invasion of a neotropical forest by native cerrado and exotic pasture grasses. Philosophical Transactions of the Royal Society of London. Series B, Biological Sciences, 368(1619), 20120427. PMid:23610179. http://dx.doi.org/10.1098/rstb.2012.0427.

Singh, A. K., Kushwaha, M., Rai, A., \& Singh, N. (2017). Changes in soil microbial response across year following a wildfire in tropical dry forest. Forest Ecology and Management, 391, 458-468. http://dx.doi.org/10.1016/j.foreco.2017.02.042.

Souza, A. F., \& Martins, F. R. (2004). Population structure and dynamics of a neotropical palm in fireimpacted fragments of the Brazilian Atlantic Forest. Biodiversity and Conservation, 13(9), 1611-1632. http://dx.doi.org/10.1023/B:BIOC.0000029326.44647.7f.

Souza, P. A., Nunes, L. A. P. L., Peixoto, G. L., \& Martins, S. V. (2015). Regrowth in post-fire area in a fragment of semideciduous seasonal forest in Viçosa-MG. Cientifica, 43(4), 407-412. http://dx.doi.org/10.15361/1984-5529.2015v43n4p407-412.

Stefanello, D., Ivanauskas, N. M., Martins, S. V., Silva, E., \& Kunz, S. H. (2010). Síndromes de dispersão de diásporos das espécies de trechos de vegetação ciliar do rio das Pacas, Querência - MT. Acta Amazonica, 40(1), 141-150. http://dx.doi.org/10.1590/S0044-59672010000100018.

van der Pijl, L. (1982). Principles of dispersal in higher plants (3rd ed.). Berlin: Springer-Berlag. http://dx.doi.org/10.1007/978-3-642-87925-8.

Xavier, K. R. F., Andrade, L. A., Fabricante, J. R., Coelho, M. S. E., \& Assis, F. N. M. (2011). Impactos pósfogo na regeneração natural em um fragmento de floresta ombrófila aberta no município de Areia, Paraíba, Brasil. R. Bras. Bioci., 9(3), 257-264. Recuperado em 10 de novembro de 2018, de http://www.ufrgs.br/seerbio/ojs/index.php/rbb/article/view/1582

Yamamoto, L. F., Kinoshita, L. S., \& Martins, F. R. (2007). Síndromes de polinização e de dispersão em fragmentos da Floresta Estacional Semidecídua Montana, SP, Brasil. Acta Botanica Brasílica, 21(3), 553-573. http://dx.doi.org/10.1590/S0102-33062007000300005.

Contribuição dos Autores: AVDC: Conceitualização, Análise formal, Metodologia, Investigação, Escrita-Primeira Redação; SVM: Conceitualização, Metodologia, Administração do Projeto, Supervisão; FTPT: Conceitualização, Metodologia, Administração do Projeto, Supervisão; DB: Conceitualização, Análise formal, Validação, EscritaRevisão e Edição. 